\title{
ATIVIDADE INIBITÓRIA DO EXTRATO EM ACETATO DE ETILA E HIDRO DESTILAÇÃO DE FOLHAS E CASCAS DE DRIMYS BRASILIENSIS SOBRE A CANDIDA ALBICANS E SOBRE O STAPHYLOCOCCUS AUREUS
}

\author{
INHIBITORY ACTIVITY OF THE EXTRACT IN ETHYL ACETATE AND HYDRO \\ DISTILLATION OF LEAVES AND BARKS OF DRIMYS BRASILIENSIS ON CANDIDA \\ ALBICANS AND ON STAPHYLOCOCCUS AUREUS
}

\section{Danielle TRATZ1; Guilherme Barroso Langoni de FREITAS²; Welligton Luciano BRAGUINI'; ${ }^{2}$ Durinézio José de ALMEIDA ${ }^{1}$}

\author{
1 - Faculdade Campo Real- pós graduação em biotecnologia - Guarapuava - PR \\ 2 - Universidade Estadual do Centro Oeste - Guarapuava - PR \\ Autor para correspondência: prof_durinezioalmeida@camporeal.edu.br
}

\section{RESUMO:}

Atualmente, cerca de $48 \%$ dos medicamentos empregados na terapêutica tem origem, direta ou indiretamente, de produtos naturais, especialmente de plantas. Dentre as plantas com alto potencial medicinal, se destaca a espécie Drymis brasiliensis. Extratos orgânicos e aquosos da espécie têm sido utilizados na medicina popular e em testes pré-clínicos para o tratamento e prevenção de diversas doenças. O presente trabalho teve como objetivo a avaliação preliminar do potencial antimicrobiano de extratos em acetato de etila e do óleo essencial obtidos da casca e folhas da espécie. Estes foram utilizados em testes antimicrobianos contra os patógenos Staphyoccocus aureus e Candida albicans. Nossos resultados demonstraram que o extrato em acetato de etila apresenta maior rendimento que a extração do óleo essencial, demonstraram ainda ausência de atividade antimicrobiana no óleo essencial, enquanto que o extrato em acetato de etila demonstrou esta ação em ambos os microrganismos testados.

Palavras-chave: Plantas medicinais. Drymis brasiliensis. Inibição de crescimento. Candida albicans. Staphyoccocus aureus.

\begin{abstract}
:
Currently, about $48 \%$ of the medicines used in therapeutics come directly or indirectly from natural products, especially from plants. Among the plants with high medicinal potential, the species Drymis brasiliensis stands out. Organic and aqueous extracts of the species have been used in folk medicine and preclinical tests for the treatment and prevention of various diseases. The present work had the objective of preliminary evaluation of the therapeutic potential of the bark and leaf of the plant, based on the products generated by the extraction in ethyl acetate and by hydro distillation. These were used in antimicrobial tests against the pathogens Staphylococcus aureus and Candida albicans. Our results revealed that the essential oil had no inhibitory action, whereas the extract in ethyl acetate demonstrated this action in both tested microorganisms.
\end{abstract}

Keywords: Medicinal plants. Drimys brasiliensis. Growth inhibition. Candida albicans. Staphyoccocus aureus. 


\section{INTRODUÇÃO}

No ambiente natural, as plantas estão expostas fatores bióticos e abióticos, com os quais se adaptam para garantir a sua sobrevivência. Ao longo do processo evolutivo, estas pressões ambientais levaram as plantas a desenvolver formas de sintetizar, e acumular uma grande variedade de metabólitos secundários. Muitos desses desempenham um papel importante na utilização terapêutica alternativa (CALLAWAY, 2002).

Estima-se que existam mais de 500.000 espécies de plantas em todo o mundo, destas apenas uma pequena percentagem foi relacionada com propriedades farmacológicas, e em muitos casos, há apenas avaliações preliminares (EMBRAPA, 2013). Atualmente, cerca de $48 \%$ dos medicamentos empregados na terapêutica tem origem, direta ou indiretamente, de produtos naturais, especialmente de plantas.

Dentre as plantas com alto potencial medicinal, se destaca o gênero Drymis e extratos orgânicos e aquosos das suas espécies têm sido utilizados na medicina popular e em testes pré-clínicos para o tratamento e prevenção de diversas doenças, destaca-se as atividades anti-inflamatória, antibacteriana, antifúngica, citotóxica, acaricida, antimalarica e reguladora do crescimento de plantas (LAGO et al., 2010, RICARDO et al, 2017; ROSADOAGUILAR, et al 2017; BEAUFAY, et al 2018).

Dentre os diversos trabalhos executados com o gênero o destaca-se o de Radomski e Marques (2005), analisando o óleo essencial extraído de cascas de indivíduos adultos da espécie Drimys brasiliensis oriundos da Região Centro-Sul do Paraná, onde verificaram a ocorrência de diversas substâncias de interesse industrial como, o $\beta$-pineno, limoneno, 4-terpineol, a-tujeno, canfeno, sabineno, mirceno, 3-d-careno, a-terpineno, $p$ cimeno, 1,8-cineol, g-terpineno, terpinoleno e cânfora, o que demonstra, o potencial da espécie como fonte de compostos com atividade terapêutica.

A espécie D. brasiliensis é uma planta nativa do Brasil conhecida popularmente por Cataia ou Casca d'anta, trata-se de uma árvore de porte médio, com 4 a 8 metros de altura, dotada de uma copa globosa e densa, é aromática e apresenta importância fitoquímica (CARVALHO et al., 2008).

Embora, esta seja uma espécie com compostos comprovadamente ativos, até onde sabemos, a extração com um éster simples, como o acetato de etila, não foi efetuada ainda, e trata-se de uma lacuna nos textos científicos sobre a espécie, bem como, a atividade antimicrobiana deste extrato sobre Staphyoccocus aureus e Candida albicans. 
Os S. aureus são cocos gram-positivos que fazem parte da microbiota humana, mas que podem provocar, pneumonia, meningite, endocardite, síndrome do choque tóxico e septicemia, tornou-se uma das espécies de maior importância no quadro das infecções hospitalares e comunitárias e tem apresentado cepas com características de resistência a antimicrobianos (ALMEIDA et al, 2017).

A C. albicans é um fungo dimorfico, que multiplica-se por brotamento e, em determinadas situações, pode produzir pseudo-hifa ou hifa verdadeira quando infectando um hospedeiro. É o agente etiológico da candidíase humana, doença que apresenta manifestações clínicas de diversidade de quadros, como candidíase cutâneomucosa e candidíase invasiva ou sistêmica. Atualmente varias cepas deste fungo tem demonstrado mecanismos de resistência o que tem levado a busca de novos compostos com propriedades antifúngicas para sua terapia (VIEIRA e DOS SANTOS, 2017).

O objetivo do trabalho, foi verificar se os extratos da casca e folha da espécie D. brasiliensis, obtidos, em Acetato de etila e óleo essencial demonstram atividade inibitória frente a S. aureus e C. albicans.

\section{MATERIAL E MÉTODOS}

\subsection{Material botânico}

A árvore selecionada, nativa, usada e identificada pelos moradores locais com sendo Cataia, localizada do Rio Jordão (25026'09,7"S e 51026'53,1"W), na cidade de Guarapuava - PR, em propriedade particular. Desta planta coletou-se folhas, casca, flores e frutos para identificação, o material botânico foi enviado para o laboratório de Engenharia florestal da Universidade Estadual do Centro Oeste do Paraná, aos cuidados do PhD. Eng ${ }^{\circ}$ Luciano Farinha Watzlawick, inscrito no CREA/RS - 88998, que identificou o material como sendo da espécie Drymis brasiliensis, sendo ela espécie nativa da região, exemplares da mesma já haviam sido armazenadas no laboratório.

A coleta deu-se em 07 de Março de 2015. Aproximadamente 2 (dois) quilogramas entre casca e folhas foram coletadas, as cascas foram retiradas na espessura de aproximadamente $10 \mathrm{~mm}$, por cortes longitudinais com o auxilio de uma lamina, tomando os cuidados necessários para uma coleta adequada, mantendo a nutrição da planta (EMBRAPA, 2013). Na data, a temperatura atmosférica média manteve-se em torno de 23ํㅡㄴ C. Nos laboratórios da Faculdade Campo Real o material vegetal foi aliquotado e 
embrulhados em papel Kraft, permanecendo em estufa de ar forçado a uma temperatura contínua de $40^{\circ} \mathrm{C}$, por aproximadamente 170 horas, até completa secagem. Com o auxilio de liquidificador doméstico, o material seco foi triturado, apresentando uma granulometria variada.

\subsection{Obtenção do óleo essencial}

Para este método usou-se o aparelho Clevenger, um sistema de arraste por vapor d'água. A extração do óleo foi realizada com 150 gramas do material vegetal triturado, folhas e cascas separadamente, e adição de $350 \mathrm{~mL}$ de água destilada em balão volumétrico com capacidade para $600 \mathrm{~mL}$, permanecendo em ebulição sob a manta aquecedora por um período de 8 horas. O rendimento foi calculado por leitura direta na graduação do equipamento, e o óleo foi armazenado em eppendorfs sobre refrigeração a $0^{\circ} \mathrm{C}$, até o momento dos testes antimicrobianos.

\subsection{Coleta e secagem do material vegetal}

A coleta deu-se em 07 de Março de 2015. Aproximadamente 2 (dois) quilogramas entre casca e folhas foram coletadas, as cascas foram retiradas na espessura de aproximadamente $10 \mathrm{~mm}$, por cortes longitudinais com o auxilio de uma lamina, tomando os cuidados necessários para uma coleta adequada, mantendo a nutrição da planta (EMBRAPA, 2013). Na data, a temperatura atmosférica média manteve-se em torno de 23ำ C. Nos laboratórios da Faculdade Campo Real o material vegetal foi aliquotado em menores quantidades e embrulhados em papel Kraft, permanecendo em estufa de ar forçado a uma temperatura contínua de $40^{\circ} \mathrm{C}$, por aproximadamente 170 horas, até completa secagem.

\subsection{Obtenção do extrato}

A extração foi realizada através de imersão da amostra em acetato de etila $70 \%$. Em recipiente de vidro âmbar foram adicionados, 100 gramas do material vegetal triturado, folhas e cascas separadamente, e submersas em $300 \mathrm{~mL}$ de acetato de etila $70 \%$, o recipiente foi fechado hermeticamente e mantido sob agitação constante por sete dias consecutivos. Após esse período a mistura foi filtrada em papel filtro, o liquido resultante foi acondicionado em um Becker aberto mantido em temperatura ambiente até ocorrer o 
processo de evaporação total do solvente, foi considerado a evaporação total, quando o produto resultante manteve o peso constante, o peso foi mensurado por três vezes em intervalos de três horas cada um, resultando em um liquido de coloração escura e de aspecto denso. O extrato foi armazenado em recipiente "Falcon", e acondicionado em refrigerador até a utilização em próxima etapa. Todo o experimento teve duração de 7 dias.

\section{4 Atividade antimicrobiana}

\subsubsection{Microorganismos utilizados}

As cepas Staphyloccocus aureus (Newp 0023), e de Candida albicans (Newp 0013) foram gentilmente cedidas pelos Laboratórios da Faculdade Campo Real. Onde são mantidas em ágar sangue (S. áureos) e ágar sabouraud (C. albicans). Ambos a temperatura de $40 \mathrm{C}$.

Os inóculos foram obtidos pelo método de diluição decimal seriada, após contagem de colônias em câmera de Neubauer (Borzani, 2001). No caso da cepa S. aureus a concentração utilizada foi de $3,8 \times 104$ UFC/ mL, este resultado corresponde aproximadamente a 0,4 na escala de Mac Farland e para C.albicans usamos 160 x UFC/mL.

A inoculação foi realizada pela técnica de espalhamento de $500 \mathrm{~mL}$ do inoculo com alça de drigalski de vidro e logo após o aguardo de 20 segundos realizado o preenchimento dos poços com $20 \mathrm{~mL}$ de cada componente, as placas inoculadas com $\mathrm{S}$. áureos foram mantidas em estufa á 37으 $\mathrm{C}$ por 48 horas até a leitura dos resultados. As placas inoculadas com C. albicans, acondicionadas em estufa como recomendado por Carvalho et al. (2002) a 25 a $27^{\circ}$ por 72 horas.

\subsubsection{Método de difusão em ágar}

Os Meios de cultura utilizados foram o Agar Miller Hinton (S. áureos) e Agar Sabouraud (C. albicans) ambos recomendados para a avaliação da resistência aos antimicrobianos (BRASIL, 2004). Relacionando o tamanho da zona de inibição de crescimento, halo, do microrganismo desafiado com a concentração da substância ensaiada (PINTO et al., 2003).

A determinação da atividade antibacteriana foi realizada pela técnica do poço, a qual consiste na utilização de placas com camada dupla de ágar, uma camada base e 
camada seed de meios adequados ao microrganismo testado, vertidos em placas de Petri 100 × 20 mm, sendo usado como base o ágar-ágar em uma concentração de $2 \%$, o dobro da recomendada pelo fabricante, a fim, de fornecer uma base mais rígida para receber o camada seed, camada esta composta pelo ágar específico para cada microorganismos, nela foram realizados poços de $3 \mathrm{~mm}$ de profundidade com $4 \mathrm{~mm}$ de diâmetro, com capacidade para receber $20 \mu \mathrm{L}$ de cada concentração, realizados manualmente 5 em cada placa: controle positivo, controle negativo, extrato a 100\%, 10\% e 0,1\%, respectivamente. O teste foi realizado em quintuplicata. Para C. albicans o controle positivo foi um antifúngico específico de amplo espectro (Nistatina ${ }^{\circledR}$ solução oral $100.000 U \mathrm{U}$ ) e para S. aureus, como controle positivo, utilizou-se um antibiótico de amplo espectro, Vancomicina® $500 \mathrm{mg}$, frasco em pó, diluído em $5 \mathrm{~mL}$ de água destilada. Como controle negativo, para o teste com o extrato bruto, foi utilizado o etanol, e no teste com o óleo essencial, Tween 80, diluído 100 $\mu \mathrm{L}$ para $10 \mathrm{~mL}$ de água destilada. Para atingir cada concentração desejada dos extratos, $10 \%$ e $0,1 \%$ os mesmos foram diluídos respectivamente em seus usuais controles negativos, e para a concentração de $100 \%$ usou-se o extrato puro.

\subsubsection{Análise estatística.}

Os resultados foram obtidos através da mediação dos halos de inibição, utilizando paquímetro digital, estes dados foram plotados em uma planilha do software statistica 2010 e analisados quanto a normalidade e homogeneidade, como se mostraram de distribuição normal e homogêneos foram avaliados pelo teste de Dunnet em comparação com os controles positivo e negativo. Foi ainda avaliada a regressão quadrática e estabelecida a equação da reta observada.

\section{RESULTADOS E DISCUSSÃO}

Os extratos demonstraram que existe diferença de rendimento para diferentes métodos de extração bem como para o órgão da planta usado para este fim. O processo de extração pelo método de hidrodestilação (óleos essenciais) teve um rendimento de 0,13\% extraído das cascas, enquanto, o óleo essencial extraído das folhas teve um maior rendimento chegando a 0,20\%. Maggioni (2017) relatou que o óleo essencial de folhas (1,09 a 1,39\%) foi significativamente superior ao teor do óleo de cascas $(0,14$ a $0,15 \%)$. Os valores obtidos por estes autores são superiores aos observados neste trabalho e, no 
entanto, o período de coleta e método de extração foram as mesmas usadas neste. Sugerese que fatores nutricionais e genéticos sejam responsáveis pela divergência nos dados, no entanto maiores avaliações, com técnicas de variabilidade genética devem ser efetuadas para testar tal hipótese.

Para a espécie Drimys winteri, Muñoz et al (2015) encontraram variações de rendimento de 0,33 a 3,33\% para extratos da casca e de 2,01 a 2,71\% para extratos das folhas em coletas efetuadas em estações climáticas diferentes, segundo Lago et al (2010) seus rendimentos foram de 0,55\% a partir de óleo de folhas e 0,18\% a partir do óleo da casca, esta variação é bem descrita em vários trabalhos científicos (LEÃO, 2007; GOBBONETO e LOPES, 2007; SILVA, 2010) e sua causa está associada as variações nos metabolitos das plantas em resposta as variações ambientais.

O extrato utilizando-se acetato de etila apresentou um rendimento de $7,8 \%$ (cascas), e 6,2\% (folhas). Lago et al (2010) encontraram para extração hexanica um rendimento de 7,3\% (casca) não relatando a extração das folhas. Segundo Silva (2010), de acordo com a época de coleta, encontra-se maior ou menor rendimento, o autor relata que coletas em plantas medicinais no mês de janeiro, apresenta rendimentos maiores, e valores menores nos meses de março a dezembro, devido ao primeiro ciclo de floração, que ocorre de forma variável dependendo do clima de cada região.

Os resultados de avaliação da atividade antimicrobiana demonstram que, os óleos essenciais, obtidos de casca e de folhas da planta, não possuem atividade inibitória sobre as cepas de S. áureos e C. albicans usadas neste trabalho, em nenhuma das concentrações utilizadas $100 \%, 10 \%$ e $0,1 \%$.

Segundo Carvalho (2008), vários autores relataram a presença mais comum dos sesquiterpenos drimânicos nos extratos de óleos essenciais da espécie, dando a eles o potencial antimicrobiano. Porém, nos testes realizados no presente trabalho, não demostraram esse potencial, relacionado a isso, Silva (2010) relata que, fatores ambientais como sazonalidade, temperatura, disponibilidade hídrica, radiação, nutrientes, altitude, entre outros, podem causar variações significativas na composição química dos óleos essenciais. Lago et al. (2008), relata a presença de monoterpenos (90\% do teor) originados pela via do Geranil difosfato pela ação da pinene synthase [EC:4.2.3.119 4.2.3.120] para o alfa pireno (Gambliel \& Croteau,1984), e da alpha-terpineol synthase [EC:4.2.3.111] para terpenolene e alpha-terpineol (Martin \& Bohlmann 2004), dentre estes o alfa pireno (39\%), alpha-terpineol (15\%) e terpinolene (10\%) são os componentes principais.

Dentre os três o alpha-terpineol já foi descrito por Soon-Nang et al (2012) como 
apresentando forte atividade antimicrobiana contra Estreptococos mutans, bactéria coco Gram-positivas.

Devido à ausência de inibição é possível inferir, que no extrato obtido neste experimento os teores de alpha-terpineol tenham sido incipiente, ou mesmo ausente, pois como descrito por Silva (2010), fatores ambientais como sazonalidade, temperatura, disponibilidade hídrica, radiação, nutrientes, altitude, entre outros, causam variações na composição química dos óleos essenciais.

Contatou-se que o extrato em acetato de etila da casca, inibiram o crescimento das estirpes de S. áureos e de C. albicans usadas neste estudo (Figura 01).

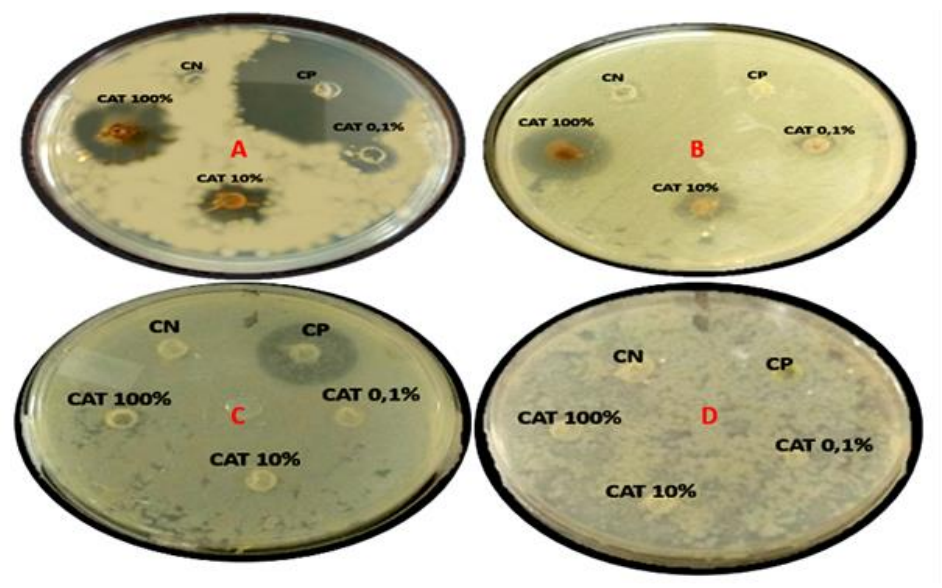

Figura 01: "A" extrato da casca de D. brasiliensis em acetato de etila contra S. áureos; "B" extrato da casca de D. brasiliensis em acetato de etila contra $C$. albicans; "C" Extrato por hidrodestilação da casca de D.brasiliensis contra S. áureos; "D" extrato por hidrodestilação da casca de $D$. brasiliensis contra $C$ albicans; $C N$, controle negativo; CP controle positivo; CAT extrato de $D$. brasiliensis.

Os dados foram testados quanto a homogeneidade de variâncias pelo teste de Levene e se mostraram homogêneas ( $F=28,72 ; p=0,001)$, foram também testados quanto a normalidade pelo teste de Shapiro Wilk e se mostraram de distribuição normal $(\mathrm{W}=0,9193$ $p=0,05)$, os testes indicam que existe diferença entre os extrato da casca, e da folha quanto a capacidade de inibição, bem como destas e do controle positivo, comparados pelo de $t$ $(t=-3,584 ; p=0,002)$ feito sobre as medidas dos halos de inibição, comprovou-se também que existe uma correlação (Figura 02 e 03) forte entre a concentração e a capacidade de inibição o que permite a afirmação de que o efeito é dose dependente. 


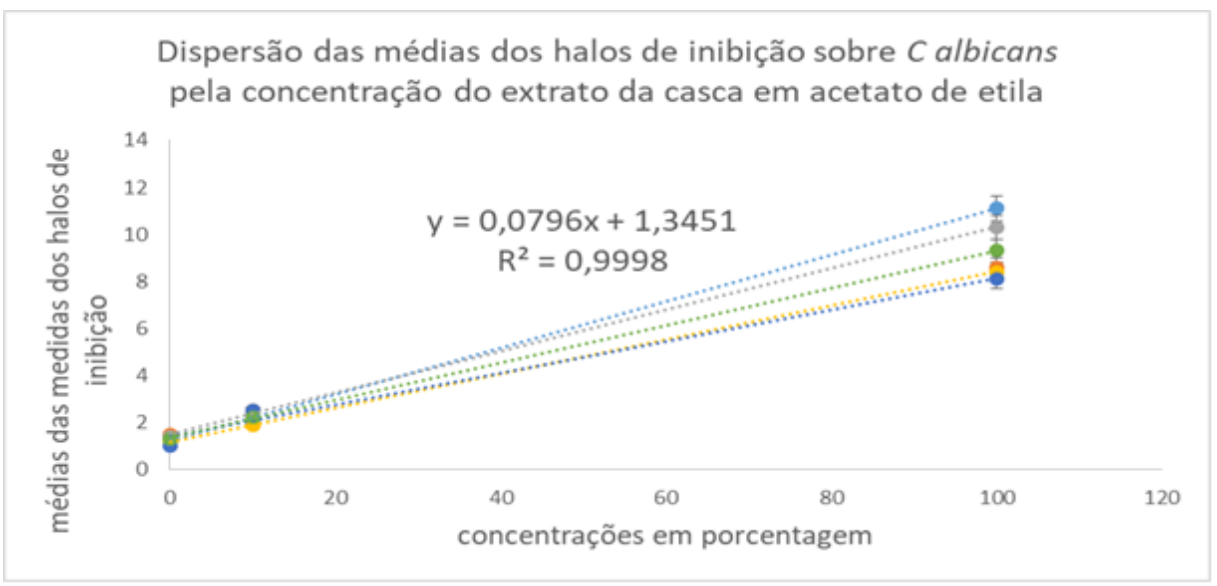

Figura 02: Dispersão, regressão quadratica e equação obtida dos resultados de raio de inibição do extrato da casca de $D$. brasiliensis extraido em acetatode etila sobre $C$. albicans

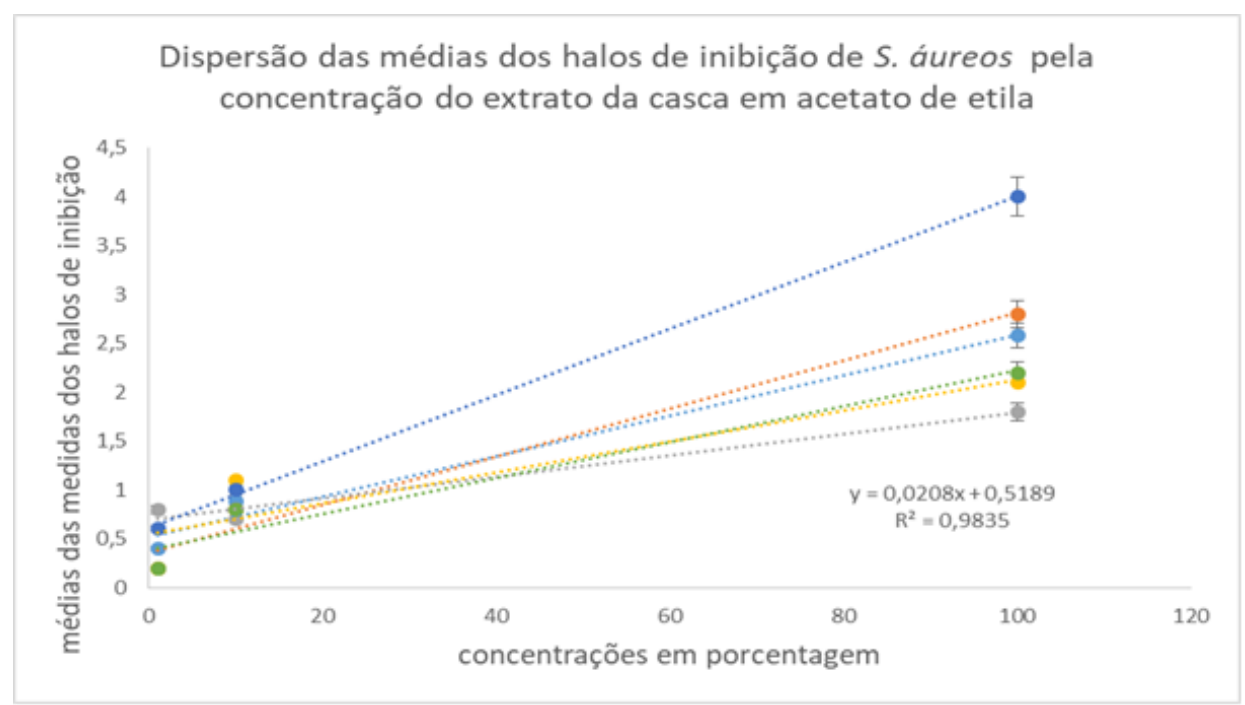

Figura 03: Dispersão, regressão quadratica e equação obtida dos resultados de raio de inibição do extrato da casca de D. brasiliensis extraido em acetato de etila sobre S. áureos.

Os resultados obtidos neste trabalho, corroboram com os observados por Malheiros et al (2005), quanto a ação antifúngica, testada por eles contra, Microsporum canis, Microsporum gypseum, Epidermophyton floccosu, Trichophyton rubrum, Trichophyton mentagrophytes, Candida tropicalis e Cryptococcus neoformans.

Silveira et al (2012), detectaram a atividade antibacteriana dos sesquiterpenos encontrados nas cascas da espécie, e os autores relatam que a ação contra bactérias Gram-positivas é mais eficaz devido a característica da membrana do patógeno e a 
capacidade do composto invadir o seu interior. As doenças infecciosas ainda são uma das principais causas de morte no mundo, sendo imperativo o desenvolvimento de novos compostos antimicrobianos. Nesse contexto a $D$. brasiliensis é uma boa fonte de compostos promissores.

\section{CONCLUSÃO}

O extrato em acetato de etila obtido de D. brasiliensis apresenta maior rendimento, tanto para casca quanto para folhas, quando comparado a extrações com outros solventes, a atividade inibitória deste extrato sobre $\mathrm{C}$. albicans e $\mathrm{S}$. áureos pode ser comprovada para extratos da casca, sendo este efeito dose dependente, o que caracteriza que a espécie é promissora fonte de compostos antimicrobianos. Os óleos essenciais obtidos não apresentaram.

\section{REFERÊNCIAS}

ANVISA, Agência Nacional de Vigilância Sanitária. Manual de Microbiologia Clínica para o Controle de Infecção em Serviços de Saúde. (2004) Módulo IV Descrição dos Meios de Cultura Empregados nos Exames Microbiológicos. SEPN 515, Edifício Omega. Bloco B, Brasília (DF), CEP 70770-502 1. Ed. 2004.

CALLAWAY, R. M. The detection of neighbors by plants. Trend Ecology Evolution. v. 17, p. 104-105, 2002.

CARVALHO L. A.C; OlIVEIRA, F. S.; TOYAMA, D. O.; FÁVERO, O. A.; ROMOFF, P.: LAGO, J. H. G. Avaliação do potencial antinociceptivo e análise fitoquímica do extrato e do óleo volátil das folhas de Drimys brasiliensis. In: Reunião Anual da Sociedade Brasileira de Química, 31. Águas de Lindóia - SP, 2008.

CARVAlHO, A. A. T., SAMPAiO, M. C. C., SAMPAiO, F. C., MELO, A. F. M., SENA, K. X. F. R., CHIAPETTA, A. A., HIGINO, J.S.; Atividade antimicrobiana in vitro de extratos hidroalcoólicos de Psidium guajava L. sobre bactérias gram-negativas. Acta Farm Bonaerense 21: 255-258. 2002. 
CECHINEL FILHO, V.; SCHLEMPER, V.; SANTOS, A. R. S.; PINHEIRO, T. R.; YUNES, R. A.; MENDES, G. L.; CALIXTO, J. B.; DELLE MONACHE, F. Isolation and identification of active compounds from Drimys winteri barks. Journal of Ethnopharmacology, Lausanne, v. 62 , n. 3, p. 223-227, 1998.

EMBRAPA Florestas. Radomski et al., Cataia (Drymis brasiliensis Miers). Colombo - PR, 2013.

GAMBLIEL H, CROTEAU R Pinene cyclases I and II. Two enzymes from sage (Salvia officinalis) which catalyze stereospecific cyclizations of geranyl pyrophosphate to monoterpene olefins of opposite configuration. JournalJ. Biol. Chem. 259 (1984) 740-8.

GOBBO-NETO, L., LOPES, N. P., Plantas medicinais: fatores de influência no conteúdo de metabólitos secundários. Química Nova. São Paulo, v. 30, n. 2, p. 374-381. 2007.

JANSEN, B., GROOT. Ocurrence, biological activity and synthesis of drimane sesquiterpenoids. Natural Product Report. v. 21. p. 449-477, 2004.

LEÃO, J.D.J. Bioatividade de extratos vegetais no controle de Sitophilus oryzae (Linné, 1973) em arroz. 2007, 91p. Tese (Doutorado) apresentada ao Programa de Pósgraduação em Agronomia. Área de concentração em produção vegetal da Universidade Federal de Santa Maria (UFSM, RS) - Santa Maria, RS, Brasil.

LORENZI, H. Árvores brasileiras: manual de identificação e cultivo de plantas arbóreas nativas do Brasil. Nova Odessa: Plantarum, 1992. 368 p. 2002.

MALHEIROS, A., CECHINEL, V. F., SCHMitT, C. B., YUNES, R. A., ESCALANTE, A., SVETAZ, L., ZACCHINO, S., MONACHE, F.D. Antifungical activity of drimane sesquiterpenes from Drymis brasiliensis using bioassayguided fractionation. Journal of Pharmaceutical Sciences. v. 8, p. 335-339, 2005.

MARTIN DM, BOHLMANN J Identification of Vitis vinifera (-)-alpha-terpineol synthase by in silico screening of full-length cDNA ESTs and functional characterization of recombinant terpene synthase. Journal Phytochemistry 65:1223-9 (2004)

MUÑOZ O, GUTIERREZ M.; GONZALEZ R.; HAMMANN S.; VETTER W. Antifungal and Insecticidal properties of the Phytoconstituents of Drimys winteri (Winteraceae) growing in 
Chiloe Island-Chile, 2015.

PINTO, T. J. A., KANEKO, T. M., OHARA, M. T.Controle Biológico de Qualidade de Produtos Farmacêuticos, Correlatos e Cosméticos. 2.ed. São Paulo: Atheneu Editora, 325 p. 2003.

RADOMSKI, M. I.; MARQUES, M. O. M. Composição do óleo essencial da cataia (Drimys brasiliensis). In: SIMPÓSIO BRASILEIRO DE ÓLEOS ESSENCIAIS, 3., 2005. Campinas. Resumos. Campinas: Instituto Agronômico, 2005. p. 65. (IAC. Documentos, 77).

SILVA, N. C. C. Estudo comparativo da ação antimicrobiana de extratos e óleos essenciais de plantas medicinais e sinergismo com drogas antimicrobianas. Dissertação (Mestrado em Biologia Geral e Aplicada) - Universidade Estadual Paulista, Botucatu, São Paulo. 2010.67p

SILVEIRA, A. C. O.; CLAUDINO, V. D.; YUNES, R. A.; CECHINEL-FILHO, V.; MALHEIROS, A.; CORDOVA, C. M. M.; BELLA CRUZ, A. Antibacterial Activity and Toxicity of Drimys brasiliensis. Latin American Journal of Pharmacy, Buenos Aires, v. 31, n. 7, p. 935-940, 2012.

SIMÕES, C. M. O.; MENTZ, L. A.; SCHENKEL, E. P.; IRGANG, B. E.; STEHMANN, J. R. Plantas da medicina popular no Rio Grande do Sul. Porto Alegre: Editora da Universidade/UFRGS, 1986. $147 \mathrm{p}$

SOON-NANG P.; YUN K. L.; FREIRE M. V.;CHO E; DONGCHUN J.; JOONG-KI K. Antimicrobial effect of linalool and a-terpineol against periodontopathic and cariogenic bacteria, Anaerobe, Volume 18, Issue 3, June 2012, Pages 369-372, ISSN 1075-9964, http://dx.doi.org/10.1016/j.anaerobe.2012.04.001. 